\title{
Uma análise sobre o documentário performático no filme Terra deu, terra come
}

\author{
Rafael Valles*
}

Resumo: Partindo do ponto de que o cinema documentário e a performance art são áreas distintas, este trabalho pretende analisar as implicações responsáveis por delimitar o que se conhece como documentário performático. Como estudo de caso, será analisado o documentário Terra deu, terra come (2010), por entender que ele traz questões para se pensar o que é um documentário performático.

Palavras-chave: cinema; documentário; performance.

Resumen: Partiendo del punto de que el cine documental y la performance artística son áreas distintas, este estudio tiene como objetivo examinar las implicaciones responsables por delimitar lo que se conoce como documental performativo. Como estudio de caso, será analizado el documental Terra deu, terra come (2010), por entender que plantea cuestiones para pensar qué es un documental performativo.

Palabras clave: cine documental; performance.

Abstract: From the point of view that the documentary film and performance art are distinct areas, this study intends to examine the implications responsible for defining what is known as performative documentary. As a case study, I will analyze the documentary Terra deu, terra come (2010), since this film brings issues to think about what constitutes a performative documentary.

Keywords: cinema; documentary; performance.

Résumé: Bien que film documentaire et art de la performance soient des domaines distincts, cette étude vise à examiner les principes qui sont à l'origine de la définition de ce qui est connu comme documentaire performatif. Comme une étude de cas, on analysera le documentaire Terra deu, terra come (La terre a donné, la terre a mangé, 2010), en considérant qu'il véhicule des interrogations permettant de réfléchir à la compréhension de ce que peut être un documentaire performatif. Mots-clés: cinema; documentaire; performances.

\footnotetext{
* Doutorando. Pontifícia Universidade Católica do Rio Grande do Sul, Faculdade de Comunicação Social, Programa de Pós-Graduação em Comunicação Social (PUCRS - FAMECOS - PPGCOM). 90619-900, Porto Alegre, Brasil. Bolsista da CAPES, Ministério da Educação do Brasil, Brasília - DF 70040-020. Email: ra.valles@hotmail.com
}

Submissão do artigo: 06 de dezembro de 2015. Notificação de aceitação: 17 de fevereiro de 2016.

Doc On-line, n. 19, março de 2016, www.doc.ubi.pt, pp. 213-225. 


\section{Introdução}

Este artigo parte do pressuposto de que o cinema documentário se constrói a partir de uma relação íntima com a performance. Dentro de um sentido mais amplo dessa relação, o real num documentário é a criação de um ato performático, é a elaboração de um ato ritualístico que revela a impossibilidade de se entender o real como mera reprodução da realidade. $\mathrm{O}$ documentário se constrói, assim, não somente a partir das suas relações de alteridade ou na sua busca por abordar um determinado contexto sócio-histórico, mas - sobretudo nas formas como o registro documental agencia o processo vivencial e efêmero entre o realizador, o suporte e o que se busca registrar.

Somente para citar o caso mais emblemático, Nanook, o esquimó (1922) não é somente um documentário sobre Nanook e sua família ou sobre a vida dos esquimós no polo norte. É também um documentário sobre a relação de Nanook com a câmera, de confrontação de um Nanook real com um Nanook representado pelo registro de Flaherty, além de ser um filme construído a partir das negociações entre o que Flaherty propunha que Nanook fizesse, mesmo que isto não significasse fazer parte do seu próprio real.

No entanto, esta questão entre documentário e performance, que, num primeiro momento, mostra-se tão evidente, começa a ser problematizada quando são analisadas as suas particularidades. De que tipo de performance e documentário estamos falando? A partir de qual contexto procuramos analisar? É dentro de questionamentos como esses que se evidenciam a proposta deste artigo: o que está em jogo aqui é como estabelecemos as relações entre performance $e$ documentário e em quais circunstâncias se constrói este diálogo?

\section{As relações entre performance e documentário}

Não são poucos os teóricos que assumem a dificuldade em delimitar o que é performance. Existem inclusive autores que acreditam que conceitualizar uma ontologia seria como limitá-la.

Qualquer definição mais exata negaria de imediato a própria possibilidade da performance, pois seus praticantes usam livremente quaisquer disciplinas e quaisquer meios como material - literatura, poesia, teatro, música, dança, arquitetura e pintura, assim como vídeo, cinema, slides e narrações, empregando-os nas mais diversas combinações. De fato, nenhuma outra forma de expressão artística tem um programa tão ilimitado, uma vez que cada performer cria sua própria definição ao longo de seu processo e modo de execução. (Goldberg, 2006: 09).

No entanto, ao possuir um sentido bastante amplo que vai desde determinadas condutas de execução civil, como cidadania e identidade sexual, até 
manifestações artísticas nas suas mais variadas formas (apresentação teatral, concerto musical, intervenções urbanas...), se faz necessário um recorte conceitual para tentar se aproximar de algumas das suas principais caracterizações.

Traduzida com a expressão não menos ampla de arte de ação, se buscou assim definir a performance enquanto uma arte de intervenção onde, como afirma Diana Taylor,

palavras tais como ação e representação dão lugar à ação individual e a intervenção. Ação pode ser definida como ato, um happening vanguardista, uma arte-ação, uma concentração ou uma intervenção política. Ação incita as dimensões estéticas e políticas de atuar, no sentido de intervir. ${ }^{1}$

Ao estar muito atrelada ao campo da arte experimental e de vanguarda de movimentos como o futurismo e o dadaísmo nos inícios do século XX, a performance se afirmou como um tipo de manifestação artística elaborada basicamente através de um performer. A performance se entendia assim enquanto uma arte do corpo, enquanto uma arte da ação pela qual o performer cria um ato efêmero, irrepetível; assim como um ato de intervenção em espaços públicos, diante de grupos, indivíduos, com o intuito de romper o sentimento de cotidianidade, para acentuar o seu caráter ritualístico.

Mas ao se delimitar este entendimento sobre performance enquanto manifestação artística, também se estabelecem conflitos. Autores como Peggy Phelan partem do entendimento de que uma performance não pode ser reproduzida ou repetida, quanto menos gravada.

O presente é a única vida da performance. A performance não pode ser guardada, gravada, documentada, ou de outra forma qualquer participar na circulação das representações: se isto ocorre, então a performance se tornará qualquer coisa menos performance. (Phelan, 1996: 146, tradução nossa).

Ou, então, como afirma Luiz Claudio Costa,

o registro faz desaparecer a obra em sua escritura supostamente própria, como objeto, porque se tornou uma experiência presencial e impermanente, onde ao mesmo tempo, desdobra a obra e a reinventa numa escritura de apropriação imprópria, uma vez que torna ausente o presente anterior, evidenciando a virtualidade de toda obra de arte. (Costa, 2009: 30).

No entanto, se a essência da performance art é a sua efemeridade e irreprodutibilidade, também o é a sua transitoriedade, o seu potencial em adaptar-se a diferentes meios, reinventar-se enquanto manifestação artística. Hoje sabemos que o audiovisual encontra-se perfeitamente integrado a este processo, tendo-se em conta que tanto a vídeo-performance como a foto-performance

1. TAYLOR, Diana. "Hacia una definición de Performance" (tradução nossa). Disponível em: http://performancelogia.blogspot.com/2007/08/hacia-una-definicin-de-performance.html 
tornaram-se importantes ramificações para um entendimento mais amplo da performance art.

Como elemento fundamental nesta aproximação, encontra-se o surgimento do vídeo em meados dos anos sessenta, fator este que abriu todo um campo de possibilidades para se pensar como a performance poderia se inserir no registro audiovisual. Como um suporte que intimava outro tipo de relação entre o realizador com a câmera, o vídeo começou a potencializar essa aproximação entre o performer e o registro da sua performance. O vídeo trazia a ideia do imediato entre a ação e sua reprodução, do ao vivo compartilhando a instantaneidade da performance. A possibilidade de ver a imagem registrada no ato mesmo do seu registro, trazia aos videoartistas a ideia do vivencial, de realizar um plano-sequência onde a montagem se encaixava no próprio ato do registro.

Com a utilização do recurso criativo do tempo real no vídeo, é possível observar que a obra passa a existir não mais como produto, ou como resultado de uma manifestação acabada, mas como processo de elaboração, que precisa ser vivenciado processualmente, na duração do ato, em seu inacabamento, como referência à vivência de um acontecimento. A obra passa a existir como forma aberta, constitutiva da construção de sentidos entre o tempo apreendido pelo homem e o tempo produzido pela máquina. (Mello, 2006: 145).

Assim, surgiram obras referenciais como Digging pieces (1971), Centers (1971), Pryings (1971), de Vito Acconci; Shoot (1971), 220 (1971), Bed piece (1972), de Chris Burden; Reflecting Pool (1977-1979), de Bill Viola, Rest energy (1980), de Marina Abramovic, entre outros, que estabeleceram uma relação de intimidade não mais propriamente com o público em si, mas com o uso da câmera como catalizadores destes atos performáticos.

Se formos pensar dentro do contexto brasileiro, a vídeo-performance também contribuiu profundamente para se expandir o entendimento de uma nova relação entre o realizador com o suporte de registro. Seja através da ausência de cortes e da ideia de experiência vivencial durante o registro, o efeito de presente, da performance frontal a câmera, como em Marca registrada (1975), de Leticia Parente, ou da câmera como prótese do olhar do realizador, como Lua Oriental (1978), de José Roberto Aguilar, a vídeo-arte trouxe uma nova perspectiva para a ação no audiovisual brasileiro. Assim como ocorreu em um contexto internacional, o surgimento do vídeo foi fundamental para se repensar o corpo e sua relação com o suporte sob uma outra perspectiva. Buscando a ideia do ao vivo, mais relacionada ao sensitivo e poético do que ao narrativo, os trabalhos em vídeo buscavam assim privilegiar a ação, o processo do corpo no seu ato performático.

Trata-se de práticas poéticas entendidas como ações performáticas, captadas em tempo real e criadas especialmente para o vídeo. O resultado situa-se no 
limite de saber onde termina o corpo e onde começa o vídeo, ou na relação dialógica entre corpo e vídeo. Encontramos nas obras desses artistas a criação de um campo nas artes em que corpo e máquina são ao mesmo tempo contexto e conteúdo interpenetrando-se na construção de significados. (Mello, 2007: 143).

Simultaneamente a isto, os anos setenta mostravam ao documentário brasileiro a impossibilidade em somente mostrar o real como ele é. Não bastava mais ao documentário tornar-se uma simples ferramenta de transformação social e de promover a denúncia das desigualdades sociais. Começaram, assim, a surgir propostas que questionaram o modo de representação realista estabelecido pelos documentários do cinema novo. É o caso do antidocumentário, proposta formulada por Arthur Omar a partir do ensaio manifesto "O antidocumentário, provisoriamente", publicado originalmente pela revista Vozes, no ano de 1972.

Omar parte da posição de que o documentário tradicional não tem capacidade para fazer o que se propõe - documentar. Congo (1972), um dos seus primeiros trabalhos, coloca em prática os seus princípios, a medida em que Omar recusa mostrar seu referente, os camponeses, e busca produzir assim uma recepção do documentário mais relacionada a sua construção, do que propriamente em documentar um outro.

Não somos parte do objeto, não podemos tomar parte dele, imersos na ilusão de recriá-lo (...) nenhum documentário é a fala de um vaqueiro, por mais que se focalize o vaqueiro e se o faça falar (...) é preciso questionar a estrutura do documentário como sendo produtor de conhecimento". (Omar, 2004: 122).

É dentro deste contexto que filmes performáticos como Di Glauber (1977) não surgiram por acaso. Ao inscrever-se na imagem, Glauber expande os conceitos no documentário nacional sobre como representar a um outro, assim como colocar-se a si próprio frente a um outro. Mais que documentar, Glauber realiza uma performance, não somente no seu caráter de criação e representação frente à câmera, mas também pelo seu caráter de intervenção, à medida que os registros feitos no velório sobre o corpo de Di Cavalcanti no caixão não foram previamente autorizados pela família. Como afirmam Consuelo Lins e Claudia Mesquita

Congo e Di/Glauber são filmes experimentais, reflexivos, ensaísticos; obras em que a intervenção dos cineastas é central e explícita, realizadas a partir de um material audiovisual heterogêneo, e nas quais o que importa não são as "coisas" propriamente, mas a relação que se pode estabelecer entre elas. Filmes que deixam claro os limites da representação documental e propõem novas formas de relação com o espectador. (Lins; Mesquita, 2008: 24). 
Na essência dessas transformações no documentário brasileiro encontra-se a explicitação de um ato performático. A abordagem documental se distancia da sua busca realista, para apostar na explicitação das intervenções que realiza sobre este real, nas escolhas dos seus dispositivos. Este tipo de performance que possui as suas raízes na performance art se insere enquanto uma atitude de transgressões e rupturas dentro do entendimento das representações no cinema documentário e da construção de caminhos para o que hoje pode se chamar como documentário performático.

\section{O documentário performático}

Para iniciar um entendimento sobre o que é um documentário performático, duas definições se tornaram referenciais. A partir de uma ótica mais empírica, dividida em modalidades, Bill Nichols define o documentário performático "como um desvio da ênfase que o documentário dá à representação realista do mundo histórico para licenças poéticas, estruturas narrativas menos convencionais e formas de representação mais subjetivas" (Nichols, 2005: 170).

Os documentários performáticos dirigem-se a nós de maneira emocional e significativa em vez de apontar para nós o mundo objetivo que temos em comum. Esses filmes nos envolvem menos com ordens ou imperativos retóricos do que com uma sensação relacionada com sua nítida sensibilidade. A sensibilidade do cineasta busca estimular a nossa. Envolvemo-nos em sua representação do mundo histórico, mas fazemos isso de maneira indireta, por intermédio da carga afetiva aplicada ao filme e que o cineasta procura tornar nossa. (Nichols, 2005: 170).

Mesmo diante de uma definição com um caráter bastante amplo e não suficientemente específico, é importante observar que Nichols ressalta o valor subjetivo na prática de documentários performáticos, onde as licenças poéticas, a maneira emocional e a sensibilidade do realizador são pontos essenciais para atingir a percepção do espectador.

Ao afirmar que este tipo de documentário se dirige aos espectadores de forma emocional e expressivamente, Nichols considera também as origens da definição do ato performático enquanto busca por uma ruptura de ordem estética e narrativa (estruturas narrativas menos convencionais e formas de representação mais subjetivas) e como experiência vivida (Envolvemo-nos em sua representação do mundo histórico) no registro e no seu processo de recepção.

Já para Stella Bruzzi, dentro de um contexto mais amplo, todos os tipos de documentários são performáticos, por entender que a negociação entre o realizador e a realidade está na performance. 
O conceito tradicional de documentário, que busca representar a realidade da maneira mais fiel possível, se estabelece sobre o pressuposto realista de que o processo de produção deve ser mascarado, como era o caso do cinema direto. Em consequência, os novos documentários performaticos proclamam uma noção distinta da "verdade" documental que reconhece a construção e ainda artificialidade do filme de não-ficção. (...) o uso de táticas de performance pode ser visto como um meio que sugere, possivelmente, que os documentários deveríam admitir a derrota da sua tentativa utópica. Deveríam apresentar, em câmbio, uma alternativa "honesta" que não busca mascarar sua inestabilidade inerente senão, ao contrário, reconhecer que a performance $\mathrm{o}$ ato documental dirigido específicamente às câmeras - será sempre o centro do filme de não-ficção. (Bruzzi, 2006: 186, tradução nossa).

Assim como em Nichols, no conceito de Bruzzi o documentário performático assume uma posição onde se recusa a representar a realidade objetivamente, trazendo assim uma diferente noção para abordar o real. Bruzzi ainda procura assumir uma abordagem mais específica, ao definir os documentários performáticos a partir de duas categorias: enquanto filmes que exibem tópicos performáticos e que visualmente são fortemente estilizados; e aqueles filmes que são inerentemente performáticos, exibindo a presença intrusa do cineasta (Bruzzi, 2006: 187).

No seu estudo sobre o tema, Bruzzi dedica especial atenção para a questão da presença intrusiva do realizador, no que ela define como performerdirector (Bruzzi, 2006: 207), ou seja, enquanto um ato performático de intervenção realizado pelo documentarista em espaços públicos, frente a autoridades ou instituições que não necessariamente concedem permissão para o registro audiovisual. Dentro deste entendimento mais específico efetuado pela autora, assumem destaque os documentários realizados por nomes como Michael Moore, Molly Dineen, Nick Broomfield, entre outros.

Na essência destes performer-directors, existe uma mescla entre o desejo em praticar um ativismo político ou uma abordagem de cunho investigativo desde as suas intervenções performáticas e uma busca por fazer um tipo de cinema documentário onde o caráter autoral assume protagonismo. Neste tipo de documentários performáticos, o foco está mais direcionado nas estratégias que os performers-directors assumem, nas intervenções que realizam e no que conseguem alcançar ou não, através deste processo. A partir do uso midiático que utilizam nos seus atos performáticos e de uma abordagem narrativa que transita entre o irônico e o sarcástico, estes filmes buscam mostrar o real desde uma perspectiva assumidamente parcial, na mesma medida em que também se assumem como entretenimento.

É por questões como estas que tanto o livro de Bruzzi como de Nichols são importantes pontos de partida neste estudo sobre o tema, por romperem certos 
tabus quanto a uma abordagem sobre o performático no cinema documentário. Por mais que ambos assumam definições que transitam em aspectos ainda muito abrangentes ou muito específicos, por outro lado terminam evidenciando as transformações que o documentário vem sofrendo nas últimas décadas.

No entanto, também é necessário afirmar que dentro de um contexto mais amplo, ainda faltam estudos que procurem aprofundar mais algumas questões sobre esta relação entre performance e documentário. Nichols, por exemplo, comenta que o documentário performático se aproxima ao campo do cinema experimental e das vanguardas, mas não consegue desenvolver de forma satisfatória esta argumentação. Bruzzi centra sua análise nos performers-directors e nos seus atos de intervenção em espaços públicos, mas também existem documentários onde a busca performática está mais concentrada na relação que se estabelece entre o realizador e o personagem registrado (como é o caso do filme Terra deu, terra come), assim como na relação do performer com o seu suporte técnico.

Além disso, tanto Bruzzi como Nichols se concentram mais em analisar o contraponto que este tipo de documentário assume diante de um tipo de documentário de cunho narrativo mais tradicional, ignorando assim a possibilidade de que existam outros elementos de ordem técnica, estética e narrativa que potencializam este tipo de diálogo entre a performance e o documentário. É diante de questões como estas que filmes como Terra deu, terra come são importantes neste processo reflexivo, na medida em que contribuem diretamente para ampliar um entendimento sobre o que pode ser um documentário performático.

\section{Terra deu, terra come}

Terra deu, terra come (2010) é um documentário que decide assumir riscos. No centro desta questão encontra-se Pedro de Alexina, um dos últimos cantadores de vissungo, as cantigas em dialeto banguela, que eram entoadas pelos africanos e seus descendentes para carregar os mortos pelo distrito diamantino, no interior do estado de Minas Gerais. Rodrigo Siqueira, o realizador de Terra deu, terra come propôs a Alexina que ele representasse um velório e um enterro como os que eram realizados pelos seus antepassados.

A começar pelo prólogo, o documentário mostra o seu desejo em buscar não somente as histórias, mas as estórias de Pedro de Alexina. Na introdução, com fundo negro sobre a imagem, Alexina conta a estória das causas pela qual uma pessoa de idade deve morrer, em uma discussão entre Jesus Cristo e São Pedro sobre as justificativas que Cristo criou para a Morte poder matar. O espectador começa a ser introduzido, assim, não somente nas qualidades de 
Alexina como exímio contador de histórias, mas também na criação de um imaginário onírico que evoca os seus antepassados.

Terra deu, terra come se propõe a registrar, através do ponto de vista e condução de Pedro de Alexina, o velório e o enterro de João Batista, um homem de 120 anos, possuidor de diamantes. Ao longo do filme, não vemos o que está por trás deste corpo coberto por um lençol e cercado por velas. Essa mesma situação permanece quando Alexina, em conjunto com sua família, vizinhos e amigos decide levar o corpo para ser enterrado.

É justamente partindo deste enigma sobre João Batista que se revela uma quebra narrativa que desafia o nosso entendimento sobre o real, que rompe os nossos pré-conceitos sobre o que definimos como documentário. O cineasta Rodrigo Siqueira conduz a sua abordagem documental a uma crença em algo que ao final do filme se revela não ser $o$ real, mas, sobretudo, uma evocação ritualística deste real. É somente na sequência final do filme, que descobrimos que o corpo de João Batista que estava sendo velado é, na verdade, um tronco de bananeira. O documentário assume, então, uma outra dimensão que o distancia de um mero registro documental do processo funeral de João Batista, para assumir uma cumplicidade com a representação de Alexina. Para alcançar esse ponto de virada, Siqueira construiu um documentário em que o real inevitavelmente deve ser constituído pelo imaginário e por uma recriação de antigas tradições dos antepassados de Alexina.

Terra deu, terra come alcança o mérito em construir uma relação de cumplicidade com Alexina, em potencializar o seu lado performático. É o que ocorre também em algumas sequências do filme, quando Alexina incorpora o próprio personagem do falecido João Batista, quando veste uma máscara de papelão. Torna-se reveladora a sequência em que o personagem João Batista (Alexina com a máscara) interage diretamente com a câmera. Ao representar João Batista, Alexina usa a câmera como um personagem que veio com uma espingarda na busca pelos seus diamantes. João Batista não somente se confronta com esta câmera, como também o camarógrafo decide assumir o personagem, entre um recuar e se aproximar de João Batista, como que buscando um duelo. Esta mesma câmera acompanha ao personagem de João Batista no mato à noite, na busca dos diamantes, indo assim além do seu papel de mero registro da ação, para tornar-se atuante no ato performático.

Mas se já não bastasse a performance buscada por Alexina, o próprio realizador Rodrigo Siqueira também realiza um trabalho de imersão neste processo performático. Em outra sequência, o personagem de João Batista (Alexina com a sua máscara) ao perguntar de onde vinha e por quem buscava, Siqueira in- 
corpora a criação de um personagem que diz procurar por "Pedro de Alexina". Entrando neste jogo, Siqueira pergunta onde estariam os diamantes.

Mais que ser uma simples performance enquanto criação de personagens ou reconstituição histórica dos seus antepassados, o que Terra deu, terra come revela é um frescor no processo vivencial conjunto entre realizador e personagem na construção deste imaginário. Alexina mostra não somente um grande carisma e uma grande sintonia na interação com Siqueira, mas - principalmente - uma plena consciência do registro e dos seus atos performáticos frente à câmera. Não por acaso, Alexina aparece nos créditos finais como um "colaborador" na direção do filme. Ao final de Terra deu, terra come, o documentarista afirma que "conseguiu apurar muitas histórias e alguns tesouros. Mas Pedro fez questão de enterrá-los sob uma ambiguidade que transita entre a verdade, a memória e a fantasia".

Vale-se observar também a participação de sua esposa e das demais pessoas que participaram do ritual fúnebre não somente como cúmplices, mas também como uma participação ativa no processo, seja em rezar pela alma do falecido, em acender velas no velório, ou em levá-lo até o morro para ser enterrado. Esta participação conjunta torna-se um importante fator para a virada final no documentário, a medida em que suas atuações reforçam uma idéia de crença coletiva em torno ao velório, mas que ao mesmo tempo revelam estar em sintonia com a proposta de Alexina, ao não mostrarem nenhuma surpresa na descoberta final em relação ao suposto corpo de João Batista.

Assistir a Terra deu, terra come também é encontrar a vigência dos princípios do ensaio "Eztetyka do sonho", escrito por Glauber Rocha em 1971. Nesse manifesto, Glauber propõe a desrazão, uma antirrazão movida pelo misticismo da cultura afro-indígena como ruptura com a razão burguesa e como ação transformadora, no que ele entendia como arte revolucionária.

Arte revolucionária deve ser uma mágica capaz de enfeitiçar o homem a tal ponto que ele não mais suporte viver nesta realidade absurda. Borges, superando esta realidade, escreveu as mais liberadoras irrealidades de nosso tempo. Sua estética é a do sonho. Para mim é uma iluminação espiritual que contribui para dilatar a minha sensibilidade afro-índia na direção dos mitos originais da minha raça. (Rocha, 2004: 251).

Terra deu, terra come não trai o espectador porque, desde o seu início, revela este universo onírico potencializado pela performance de Alexina e pelas relações ritualísticas estabelecidas entre o realizador, a câmera e Alexina. Este filme evoca a desrazão, potencializa o caráter transitório do real no documentário, revelando que o real é uma soma de elementos compostos por fatos, imaginários, criações, fábulas e, sobretudo, crenças; e isso que também o afirma enquanto documentário performático. 


\section{Considerações finais}

Historicamente a performance art de alguma forma sempre esteve envolvida na busca por uma renovação estética na arte. Seja através dos manifestos futuristas no início do século XX, nas apresentações surrealistas nos anos vinte e trinta, passando pela ideia do ato performático que surgiu como liberação da obra de arte dos museus nas décadas de sessenta e setenta, a performance se afirmou como uma prática que buscou romper com os formatos estabelecidos da arte.

Esta questão termina por revelar o caráter transitório e resistente da performance enquanto restringir sua atuação a um conceito. Assim como sucede com a performance, para o cinema documentário também resulta complexa uma conceitualização, por tratar-se de uma prática audiovisual que ao longo da sua história sempre procurou ampliar suas fronteiras e tornar-se responsável por abarcar formas que reafirmam sua diversidade. Tanto a performance como o cinema documentário são duas áreas que se transformam, que expandem suas fronteiras constantemente, de acordo ao contexto e a cultura em que estão inseridos.

Por esta mobilidade, o diálogo entre performance e cinema documentário se converteu em um dos fatores da renovação ocorrida dentro do campo documental a partir dos anos sessenta, assim como foi responsável pela ampliação do campo de atuação da performance no âmbito audiovisual. Inserindo-se num contexto onde a preponderância da subjetividade problematizou a representação do real e o documentário contemporâneo conseguiu desprender-se da imposição do real, a performance se colocou como um dos instrumentos de renovação e ao mesmo tempo de paradigma para a prática documental.

$\mathrm{O}$ ato performático no documentário produz assim uma duplicidade entre a experiência vivencial durante o registro documental e, ao mesmo tempo, a plena consciência no desdobramento da sua representação. Se trata de um outro que surge da mescla entre o criado e o documentado, partindo do fato de ser a si próprio e ao mesmo tempo ter a conciência de assumir-se como outro. O sujeito no documentário performático possui plena conciência de sua representação e por isto a manipula. Neste sentido, o documentário performático termina por problematizar a afirmação de Nichols, quando o autor afirma que esta prática move com o emocional do espectador no sentido de promover uma identificação do espectador com o sujeito do documentário performático. O documentário performático evoca o lado emocional do espectador, mas enquanto isto se refira ao ato performático como provocação, que revele uma situação de incomodidade, levando o espectador a questionar suas convicções 
sobre a prática documental, ao evidenciar que o real surge como ato de criação e intervenção sobre este real.

Um dos principais fatores para o surgimento do performático, se encontra na introdução do vídeo nas produções documentais. Com a introdução do vídeo, o documentário performático surge assim deste diálogo com a vídeoperformance e o documentário contemporâneo, através de produções de cunho mais experimental, com abordagens mais subjetivas, que descartam assumir uma dicotomia entre o real e o imaginário, o factual e o criado, construindo assim a sua verdade a partir de todos estes elementos mesclados. Em meio a isto se encontra a ação, o corpo em ação, buscando dar uma maior prioridade a vivencia deste processo que propriamente ao seu desfecho.

É dentro deste contexto que filmes como Terra deu, terra come possuem a sua importância para o entendimento de como a potencialização do lado performático termina ampliando um entendimento sobre as abordagens do real, dentro do cinema documentário.

\section{Referências bibliográficas}

Bruzzi, S. (2006). New documentary: a critical introduction. New York: Ed. Routhledge.

Costa, L.C. (2009). Uma questão de registro. In L.C. Costa (org). Dispositivos de registro na arte contemporânea. Rio de Janeiro: Contra Capa Livraria/FAPERJ.

Goldberg, R. (2008). A arte da performance. São Paulo: Martins Editora.

Lins, C. \& Mesquita, C. (2008). Filmar o real-sobre o documentário brasileiro contemporáneo. Rio de Janeiro: Jorge Zahar.

Mello, C. (2006). Extremidades do vídeo. São Paulo: Senac São Paulo.

Mello, C. (2007). Arte nas extremidades. In A. Machado (org.), Made in Brasil - Três décadas do vídeo brasileiro. São Paulo: Iluminuras.

Nichols, B. (2005). Introdução ao documentário. Campinas: Papirus.

Omar, A. (2004). O antidocumentário, provisoriamente. In F.E. Teixeira (org.), Documentário no Brasil - tradição e transformação. São Paulo: Summus.

Phelan, P. (1996). Unmarked - The politics of performance. New York: Ed. Routhledge.

Rocha, G. (2004). Revolução do cinema novo. São Paulo: Cosac Naify.

Taylor, D. (2007). Hacia una definición de Performance. http://performancelo gia.blogspot.com/2007/08/hacia-una-definicin-de performance.html 


\section{Filmografia}

220 (1971), de Chris Burden.

Bed piece (1972), de Chris Burden.

Centers (1971), de Vito Acconci.

Congo (1972), de Arthur Omar.

Di Glauber (1977), de Glauber Rocha.

Digging pieces (1971), de Vito Acconci.

Lua Oriental (1978), de José Roberto Aguilar.

Marca registrada (1975), de Leticia Parente.

Nanook, o esquimó (1922), de Robert Flaherty.

Pryings (1971), de Vito Acconci.

Reflecting Pool (1977-1979), de Bill Viola.

Rest energy (1980), de Marina Abramovic.

Shoot (1971), de Chris Burden.

Terra deu, terra come (2010), de Rodrigo Siqueira. 